\title{
Prevalence of vitamin D level in the serum of patients living in Erbil city, Iraq, referred to private clinical laboratory and effect of age and sex on it
}

\author{
Rabar M. Abdulrahman, Balen Muhsin Abdul Rahman \\ Faculty of Science and Health, Medical Microbiology Department, University of Koya, Erbil, Iraq
}

\begin{abstract}
This retrospective study aimed to determine the levels of 25 hydroxyvitamin D [25-(OH) D] in the individuals that have been referred to two laboratories (Bio Lab and King Lab) and to around 50 private side laboratories that use both Bio Lab and King Lab as a referral lab for their tests, in Erbil city, Iraq. Then show the range of deficiency and its relation with sunlight exposure, sex and age. Out of the total number of cases $(\mathrm{N}=10823)$, large percentage (nearly 78\%) referred to both clinical laboratory based in Erbil city were found to have a deficiency in vitamin D levels, which means they had 25-(OH) D levels lower than $20 \mu \mathrm{g} / \mathrm{L}$. This study found the percentage of vitamin D level in the serum of groups insufficient, deficient, adequate, optimal; intoxication were 52.8, $24.1,11,12$ and $0.2 \%$ respectively. When the records have been compared according to gender, the results suggested that there was no difference between male and female within the study population $(\mathrm{P}>0.05)$, while there was difference in the grouped ages $(\mathrm{P}<0.05)$. Our results indicate that although Erbil is located in a Mediterranean country, people living there should periodically check their 25-(OH) D levels, in order to get appropriate
\end{abstract}

Correspondence: Rabar M. Abdulrahman, Faculty of Science and Health, Medical Microbiology Department, University of Koya, Erbil, Iraq.

E-mail: raber82@gmail.com

Key words: 25-hydroxyvitamin D deficiency; Seasonal variations; Vitamin D.

Contributions: the authors contributed equally.

Conflict of interest: the authors declare no potential conflict of interest.

Funding: none.

Received for publication: 14 July 2017

Revision received: 28 November 2017

Accepted for publication: 28 December 2018.

CC Copyright R.M. Abdulrahman and B.M.A. Rahman, 2018

Licensee PAGEPress, Italy

Journal of Biological Research 2018; 91:6916

doi:10.4081/jbr.2018.6916

This article is distributed under the terms of the Creative Commons Attribution Noncommercial License (by-nc 4.0) which permits any noncommercial use, distribution, and reproduction in any medium, provided the original author(s) and source are credited. supplements of vitamin D, which eventually prevents secondary chronic disease due to vitamin D deficiency.

\section{Introduction}

Vitamin D, acquired by humans through diets, exposure to sunlight and from the supplements, is a steroid hormone, soluble in fats and usually converted to active form like 25-hydroxyvitamin D3 (25-OHD) in liver and kidney. ${ }^{1}$ It has been recognized for having critical role in calcium homeostasis and bone health. Practically vitamin D can be found in the form of vitamin D2 (Ergocalciferol) and vitamin D3 (Cholecalciferol). Most body cells and tissues have receptors for vitamin D as well as the enzymatic machinery that enables them to convert vitamin D, 25hydroxyvitamin $\mathrm{D}$, to the active form, 1,25-dihydroxyvitamin D. There are several roles linked to vitamin D in general such as homeostasis of calcium and phosphate, regulation the inhibition of parathyroid hormones $(\mathrm{PTH})$, cancer pathogenesis, involvement in the deregulation of macrophages as well as suppression of T-cells and erythropoiesis. ${ }^{2}$ When the level of 25 -hydroxyvitamin D is suppressed, it leads to an increase in the level of PTH, which in return leads to defects in bone mineralization such as osteomalacia and bone loss (osteoporosis). ${ }^{3}$

Clinical laboratories are determining the level of a 25-hydroxy vitamin D (calcidiol) in blood, which reflects the total level of vitamin $\mathrm{D}$ in the body. This is the best recommended and sensitive test for vitamin D level determination. ${ }^{4}$ Recommendation on the level of Vitamin D in serum has been set on $30 \mathrm{ng} / \mathrm{mmol}$ by most experts and studies. ${ }^{5}$ Lower than this range can be determined as Vitamin D deficiency, which has been found as an important issue in public health because it has been linked with a wide range of diseases and chronic conditions such as osteoporosis, cancer and metabolic syndrome. ${ }^{1}$ However, vitamin D deficiency affects the musculoskeletal system, but growing evidence suggests that vitamin D affects the cardiovascular system as well. ${ }^{6}$ There are several factors causing the reduction in the level of $25(\mathrm{OH})$ vitamin $\mathrm{D}$ in serum, such as short exposure to sun, eating foods and diaries that are not adequate in containing vitamin $\mathrm{D}$.

The level of vitamin D produced by a fair skinned individual in the United Kingdom has been measured to be around 2000 IU/30 minutes of exposure to sunlight. ${ }^{7}$ Furthermore, a Canadian research indicated that the prevalence of vitamin D insufficiency was changing by season's time: it was generally lowest in the summer and highest in the fall and winter, from which more than $20 \%$ of the participant were low in vitamin D level. ${ }^{8}$ In this study conducted between May 2013 and May 2017 - the results of vitamin D level in individuals performed tests in two private laboratories (Bio Laboratory and Kind Laboratory), both located 
in two main private clinical sites in Erbil city, Iraq. Both laboratories have been taken into account, due to them been used as a referral lab and most of the side labs, private clinical labs and some private hospitals sending their tests to be performed in both labs.

\section{Materials and Methods}

The subject of this retrospective study is about the individuals referring to clinical laboratories in Erbil city, Iraq. For this kind of study formal consent is not required. Data has been collected between May 2013 and May 2017. More than 12000 vitamin D tests have been performed during that period, within both Laboratories, while only 10823 results have been taken into account. The rest was not included in this study due to lack of information such as age and sex.

Individuals directly visited in both laboratories for periodical checkups between May 2013 and May 2017 have been selected as a control group $(\mathrm{N}=537)$.

Blood samples have been taken from the participant of this study in vacutainer tubes under sterile conditions. Then it has been centrifuged to separate the serum and directly processed to the Roche E411 Analyzer, with Vitamin D kit loaded on board.

\section{Methods}

Cobas E411 Analyzer from Roche Company has been used to process the samples and vitamin D kit was on board during the processing time. $1 \mathrm{ml}$ of the serum from each patient has been transferred into designed Tubes, then loaded on the analyzer.

The patients have been divided according to the level of vitamin $\mathrm{D}$ in their serum into Intoxication $\geq 70 \mu \mathrm{g} / \mathrm{L}$, Adequate group 30$70 \mu \mathrm{g} / \mathrm{L}$, Insufficient group 20-30 $\mu \mathrm{g} / \mathrm{L}$, Deficient group $<20 \mu \mathrm{g} / \mathrm{L} .{ }^{9}$ Additionally, the groups have been divided according to age and sex.

\section{Statistical analysis}

The significance in the mean values of the groups has been compared using Statistical package for social science version 14.0 for Windows program. Means of Standard Deviation (SD) for all data have been then calculated using Student t-test; those with $\mathrm{P}<0.05$ have been considered as statistically significant.

\section{Results}

In this retrospective study, the results of vitamin D level in patients referring to Bio lab and King lab, as well as to more than 50 side labs related to both laboratories have been taken into account. During May $1^{\text {st }} 2013$-May $1^{\text {st }} 2017$ period more than 12000 vitamin D tests have been performed, while only 10823 results have been taken into account. The rest was not included in this study due to lack of information such as age and sex. Control group has been selected according to those who have visited the laboratory for checkups only, without referrals $(\mathrm{N}=537)$ during the mentioned period of time. A total of 537 records has been set as a control group with the mean \pm SD of vitamin D level in their serum (16.80 \pm 17.88$)$.

The participants have been categorized according to gender and age into for groups: those with vitamin D level in their serum Intoxication $\geq 70 \mu \mathrm{g} / \mathrm{L}$, Adequate group $30-70 \mu \mathrm{g} / \mathrm{L}$, insufficient group 20-30 $\mu \mathrm{g} / \mathrm{L}$, Deficient group $<20 \mu \mathrm{g} / \mathrm{L} .{ }^{9}$ The ratio of female participants was higher than male one, as the female tested for vitamin D level was $74.3 \%$ while male was only $25.3 \%$ (Table 1 ).

In Table 2 records have been grouped into four groups according to age. Those aged under 20 years old (group 1), from 20 to 40 years old (group 2), from 40 to 60 years old (group 3) and more than 60 years old (group 4). The results show that those aged between 20 to 40 years old has been referred to vitamin $\mathrm{D}$ level test more than those aged 40 to 60 years old. While the other two groups are lower in testing for vitamin D deficiency.

On the other hand, test records have been grouped according to their vitamin D level in blood. Those with level below $20 \mu \mathrm{g} / \mathrm{L}$, considered as deficient group, compromise the highest rate among the patients $76.9 \%$, while those with vitamin D level between 20 to $30 \mu \mathrm{g} / \mathrm{L}$ were considered as insufficient group; Optimal groups (30$70 \mu \mathrm{g} / \mathrm{L})$ and Intoxication ( $>70 \mu \mathrm{g} / \mathrm{L})$. They compromise as $11 \%$, $12 \%$ and $0.2 \%$ respectively (Table 3 ).

Using independent $\mathrm{t}$ test, $\mathrm{F}$ value and the significance of difference between the mean of both male and female participants has been statistically calculated. The mean for level of vitamin $\mathrm{D}$ in serum of the entire group has been calculated as 14.77 with $\mathrm{SD} \pm 20.923$. However, when the mean of the serum level of vitamin D in male group was calculated (15.05) with $\mathrm{SD} \pm 16.88$, it was higher than female group, which was (14.67) with $\mathrm{SD} \pm 22.149$ (Table 4).

An independent-samples t-test was conducted to compare the mean of both male and female groups. There was a significant difference in male groups $(\mathrm{M}=15.05, \mathrm{SD}=16.88)$ and female group $(\mathrm{M}=14.67, \mathrm{SD}=22.149)$ conditions; $\mathrm{t}(10823)=0.841, \mathrm{P}=0.400$. These results suggest that the significant difference value of the population was higher than $0.05(\mathrm{P}>0.05)$, thus the null hypothesis

Table 1. Percentage of the study population according to gender.

\begin{tabular}{lcc} 
Parameter & Frequency & Percentage \\
Female & 8043 & $74.3 \%$ \\
Male & 2782 & $25.7 \%$ \\
\hline Total & 10825 & $100.0 \%$ \\
\hline
\end{tabular}

Table 2. Percentage of study population according to age.

\begin{tabular}{lcc} 
Parameter & Frequency & Percentage \\
Under 20 & 1282 & $11.8 \%$ \\
Between 20 and 40 & 4579 & $42.3 \%$ \\
\hline Between 40 and 60 & 3547 & $32.8 \%$ \\
More than 60 & 1417 & $13.1 \%$ \\
\hline Total & 10825 & $100.0 \%$ \\
\hline
\end{tabular}

Table 3. Percentage of study population according to level of vitamin $D$ in blood.

\begin{tabular}{lcc} 
Parameter & Frequency & Percentage \\
Deficient & 8319 & $76.9 \%$ \\
Insufficient & 1186 & $11.0 \%$ \\
\hline Optimal & 1301 & $12.0 \%$ \\
Intoxication & 19 & $0.2 \%$ \\
\hline Total & 10825 & $100.0 \%$ \\
\hline
\end{tabular}


has been accepted and statistically confirmed there were no difference between the two groups (Table 5).

On the other hand, when we calculated the differences in vitamin $\mathrm{D}$ level in serum regarding the grouped ages, we divided the patients into four groups: up to 20 years old (group 1), 20-40 years old (group 2), 40-60 years olds (group 3) and 60-highest (group 4), by comparing their means and using one-way analysis of variance (ANOVA) test (Table 6).

A one-way ANOVA between age groups was conducted to compare the effect of age on vitamin D level in blood. There was a significant effect of age on the level of vitamin $\mathrm{D}$ level in blood $(\mathrm{P}<0.05)$ within all the four groups $[\mathrm{F}(3,10821)=10.086, \mathrm{P}=0.001]$. The result was showing significance in the level of vitamin $\mathrm{D}$ in the serum of grouped individuals (Table 7).

Table 4. Mean ( \pm standard deviation, $S D)$ values of serum concentrations of $25(\mathrm{OH}) \mathrm{D}$ of both gender group.

\begin{tabular}{lcc} 
Parameter & N & Mean \pm SD \\
Male & 2782 & $15.05 \pm 16.888$ \\
Female & 8043 & $14.67 \pm 22.149$ \\
\hline
\end{tabular}

Table 5. Independent-samples t-test conducted to compare the mean of vitamin $D$ level in blood between male and female groups.

\begin{tabular}{ccccc} 
F & Sig. & $\mathrm{t}$ & df & Sig. (2-tailed) \\
.479 & .489 & -.841 & 10823 & .400 \\
& & -.957 & 6303.026 & .339 \\
\hline
\end{tabular}

Table 6. Mean ( \pm standard deviation, SD) values of serum vitamin $25(\mathrm{OH}) \mathrm{D}$ concentrations of all age groups.

\begin{tabular}{lccc} 
Groups (age) & N & Mean & SD \\
Lowest-20 & 1282 & 17.37 & 34.797 \\
$20-40$ & 4579 & 14.21 & 22.099 \\
\hline $40-60$ & 3547 & 14.12 & 13.134 \\
$60-$ highest & 1417 & 15.84 & 15.193 \\
\hline Total & 10825 & 14.77 & 20.923 \\
\hline
\end{tabular}

Table 7. A one-way analysis of variance between age groups was conducted to compare the level of vitamin $\mathrm{D}$ in blood.

\begin{tabular}{lcccc}
\hline Age groups & df & Mean Square & F & Sig. \\
Between Groups & 3 & 4404.225 & 10.086 & .000 \\
Within Groups & 10821 & 436.688 & & \\
\hline Total & 10824 & & & \\
\hline
\end{tabular}

Table 8. Mean ( \pm standard deviation, SD) of both control and test groups.

\begin{tabular}{lccc} 
& N & Mean & SD \\
Control & 537 & 16.8078 & 17.88548 \\
Tested & 10823 & 14.86 & 21.729 \\
\hline
\end{tabular}

Finally, when both means of control and test group have been calculated, they have been found to be under $30 \mu \mathrm{g} / \mathrm{L}$; this is a deficiency in vitamin D level within the test population (Table 8).

\section{Discussion}

The main goal of this prospective study was to determine the deficiency level of vitamin D in Erbil city, Iraq. In addition, to determine the effect of age and sex on the level of vitamin $D$ in the serum. In this study, high percentage of vitamin D deficiency was noticed from individuals living in Erbil city. This finding is in agree with previous study conducted by Issa and Ibraheem. ${ }^{10}$ However, Erbil area has a semi-arid climate that is very hot and dry during summer while wet and cold in winter. Also, this area has four seasons but most of the time there are sunny days. Thus, the expectation for the vitamin D level in the serum of the population should be high but when both control and test group computed for the mean of vitamin D level (Table 8), there were a noticeable deficiency in the level within both groups as the mean for control group were 16.8 and test group were 14.86. This compared to the cutoff vitamin D level $(\geq 30 \mu \mathrm{g} / \mathrm{L})$ outlined by Saleh et al. ${ }^{9}$ are much lower and considered as deficient.

The participants of this study have been categorized considering gender and age in to those with the level of Vitamin D in their serum into Intoxication $\geq 70 \mu \mathrm{g} / \mathrm{L}$, Adequate group $30-70 \mu \mathrm{g} / \mathrm{L}$, insufficient group 20-30 $\mu \mathrm{g} / \mathrm{L}$, Deficient group $<20 \mu \mathrm{g} / \mathrm{L} .{ }^{9}$ Females found to be most of the participant that have been referred for vitamin D level detection and the ratio of female participant $(74.3 \%)$ was higher than male $(25.3 \%)$ (Table 1). This is due to the fact that females in this area are more likely to stay at home and exposing less to the sunlight, which in return leads to deficiency. However, when the independent $t$ test was used to compare the means between both groups, there were significant difference; value of the population was higher than $0.05(\mathrm{P}>0.05)$, thus the null hypothesis accepted and statistically confirmed, there were no difference between the two groups, which is in disagree with previous study by AlHorani. ${ }^{11}$ It might be due to the high temperature in this area which makes both male and female tend to stay away from direct sunlight; the level of intake vitamin $\mathrm{D}$ from the vegetables is small because of less consuming them.

The records have been grouped based on their ages into four groups. Those aged under 20 years old (group 1), from 20 to 40 years old (group 2), from 40 to 60 years old (group 3) and more than 60 years old (group 4). The results show that those aged between 20 to 40 years olds has been referred to vitamin D level test more than those aged 40 to 60 years old. While the other two groups are lower in testing for vitamin D deficiency. However, the mean level of vitamin D in the serum of all group showed that they all suffer from deficiency but using one-way ANOVA test the $\mathrm{P}$ value found to be smaller than $0.05(\mathrm{P}<0.05)$ which was 0.001 , thus statistically the null hypothesis accepted and confirmed there are differences in the vitamin D level between the grouped ages. This finding is in agree with previous study conducted by Gallagher ${ }^{12}$ indicating that aging leads to the reduction in the calcitriol form of vitamin $\mathrm{D}$ to half, due to reduction in the renal functions as well as reduction in the absorption of calcium.

When all records grouped based on the level of vitamin $\mathrm{D}$ in their serum (Table 3), the findings were that deficiency in the population is high and nearly $78 \%$ of the Erbil city population suffer from vitamin D deficiency, with the level of vitamin D in their serum were below $30 \mu \mathrm{g} / \mathrm{L}$ and needs urgent reaction to lower the rate. 


\section{Conclusions}

The results show that the vitamin D level was below $30 \mu \mathrm{g} / \mathrm{L}$ for $78 \%$ of the participants. On the other hand, gender-based grouped records did not show any effect on vitamin D level; age can affect the level, as showed by the statistically difference between the grouped ages. Due to high proportion of vitamin D deficiency within the patients referred to the clinical laboratory Erbil, we recommend mandatory tests for the all individuals living there.

\section{References}

1. Holick M. Vitamin D deficiency. N Engl J Med 2007;357:26681 .

2. Smith M. Seasonal, ethnic and gender variations in serum vitamin D3 levels in the local population of Peterborough. Biosci Horizons 2010;3:124-31.

3. Bozkurt S, Berat MA, Fatma Y, et al. Age, sex, and seasonal variations in the serum vitamin D3 Levels in a local turkish population. Turk J Rheumatol 2014;29:14-9.

4. Heaney RP. Functional indices of vitamin D status and ramifications of vitamin D deficiency 1-4. Am J Clin Nutr 2004;25:1706-9.
5. Zangana SN, Mahmood MS, Ismael SA. 25-Hydroxyvitamin D and parathyroid hormone levels and their associations with left ventricular hypertrophy in a sample of hypertensive patients in Erbil-Iraq. Int J Acad Res Dev 2016;1:32-6.

6. Li Y, Kong J, Wei M, et al. 1,25 Dihydroxyvitamin D3 is a negative regulator of renin angiotensin system. J Clin Invest 2002; 110:229-38.

7. Pearce SH, Cheetham TD. Diagnosis and management of vitamin D deficiency. BMJ 2010;340:b5664.

8. Rucker D, Allan JA, Fick GH. Vitamin D insufficiency in a population of healthy western Canadians. CMAJ 2002;166: 1517-24.

9. Saleh BOA, Zainab N, Khawla AA. Research article status of serum 25 hydroxyvitamin $\mathrm{D}$ and the prevalence of its deficiency in Iraqi healthy men: age dependent study. Int J Curr Res 2016;8:28605-9.

10. Issa AM, Sana AI. Alterations of vitamin D level in Sera of Iraqi population. J Kerbala Univ 2007;5:58-64.

11. Al-Horani H, Wael AD, Eyad M, et al. Nationality, gender, age, and body mass index influences on vitamin $\mathrm{D}$ concentration among elderly patients and young Iraqi and Jordanian in Jordan. Biochem Res Int 2016. Available from: https://doi.org/1 0.1155/2016/8920503.

12. Gallagher JC. Vitamin D and aging. Endocrinol Metabol Clin North Am 2013;42:319-32. 